\title{
Some personal observations of SALT, Suggestopedia and other accelerative learning methods in Japan and Europe
} Sigrid Gassner-Roberts

During the last six months of 1984 , the author of this paper travelled to Japan and to several Western European countries, investigating Suggestopedia and other accelerative learning methods. The original suggestopedic method as developed by Dr Georgi Lozanov has undergone many changes and adaptations to suit the cultural and political situation of individual countries. This article gives an overview of the changes and adaptations made by the different countries as well as an evaluation of the amount of success with which a given country has adapted Suggestology to suit its own particular needs and circumstances.

Gedurende die tweede helfte van 1984 het die skrywer van hierdie artikel na Japan, sowel as na verskeie Wes-Europese lande gereis met die doel om ondersoek in te stel na Suggestopedagogiek en ander versnellingsmetodes in die onderwys. Die oorspronklike suggestopediese metode soos ontwikkel deur Dr Georgi Lozanov, het baie veranderinge ondergaan en is aangepas om in te skakel by die kulturele en politieke omstandighede van die onderhawige lande. Met hierdie artikel word 'n oorsig gegee oor die veranderings; die aanpassings word bespreek en die skrywer gee 'n evaluering van die mate van sukses wat daarmee behaal is.

In 1984 I spent seven months in Japan and Europe in pursuit of SALT, Suggestopedia and other accelerative learning methods, visiting institutions, schools, universities, psychologists and teachers in pursuit of my objectives. My first stop was Tokyo where I was taken to the Institute of Suggestology. I immediately sensed that it would not be easy to find out the true state of accelerative learning in Japan. Japanese politeness is probably unsurpassed and so is face saving. Everybody I came in contact with was extremely co-operative, but rather evasive in answering my direct questions. For days all I could find out was that all was well regarding SALT, but no detailed answers to my questions, not even phone numbers of people who I knew were actively involved in SALT. I became very frustrated when I realised that my direct approach was a culture shock to the Japanese. On my sixth day there I was scheduled to speak at the Institute of Suggestopedia about
SALT in Australia. After five hours of a rather one-way conversation suddenly doors opened. I obtained addresses, phone numbers, information. I was so perplexed that I asked why I had not been given all this information when $I$ inquired the first and second time. The answer was: We had to find out about you first before we wanted you to find out about us. Then I heard of Westerners and Japanese who are involved in SALT in private business and in universities, that is Sanno University, of Westerners who had conducted workshops there. I heard-and this is now something that repeated itself in European countries - of positive emotional responses to workshops that in the end amounted to very little, because Western SALT is foreign to Japanese thinking. One Westerner in particular told me about the problems he has to overcome when he conducts English classes. I told him frankly that I could not help him since I was not familiar enough with the character of the Japa- 
nese people nor with their culture. Judging by all I heard at the Institute and later in Japanese homes, SALT in Japan is faced with very special problems. In my discussions I learned that numerous people believe or "make believe" that they understand SALT and apply it in various settings. It became clear to me that few people if any have found the formula for adapting SALT to Japanese culture. One significant example: my Japanese friend was asked to help with the translation of the book "Superlearning" into Japanese. Much of "Superlearning" deals with the para-normal. In this proposed translation all mention of anything para-normal would be eliminated, because, according to the psychologist who is doing the translation, the para-normal has no room in Japanese society. I became very aware in Japan of the importance of considering community, teacher and student attitudes when one wishes to introduce SALT; in fact, in my travels around Europe this awareness became almost an obsession with me. I am now convinced that no Westerner will ever be able to teach with SALT in Japan successfully, unless he has lived there for a very long time and knows Japanese life, culture and history and with it Japanese present and past concepts and attitudes to education extremely well. Japanese cultural attitudes are still so different from Western attitudes that the success of Western SALT is problematic. I heard of many language courses conducted by Westerners with Western SALT being only marginally successful, and some people have even sued their teachers. In one case a socalled Japanese SALT teacher refused to speak to me, when he was told that I wanted to discuss Japanese SALT with him and he said to my Japanese intermediary who translated his answer to me that he did not want to speak to anybody who was serious about SALT. I was shocked to find out how many people have jumped on the band wagon there and may be doing more harm than good.

My next stop was Copenhagen, where I spent several days with Vibeke Cristofoli, a teacher of mainly South American political refugees who were freed by Amnesty International and sent to Denmark, where they are living on permanent unemployment benefits in a new form of ghetto, a hotel. Why should they learn Danish, since they will never get a job, never have a home of their own, never really mix with Danish people, everything being provided for them? Vibeke teaches them Danish, but not only that, she teaches them life, how to forgive those who betray them under torture, how to cope with physical pain caused by past torture, how to gain mental health again after long periods of inhuman suffering. SALT in Denmark has been greatly influenced by her. Lately she has begun teaching patients recovering from a stroke how to cope, and in the course of it, they learn to speak and communicate in other ways. She now conducts workshops all over Denmark and also in Sweden. Her SALT is markedly different from any other SALT I have come across.

As in Denmark, there is great interest in SALT in Sweden, but only few people actually use some or all of it. Swedish SALT is being developed cautiously and slowly. I spoke to a number of teachers in Tierp and Uppsala who showed tremendous interest but were rather timid in the application of SALT in the classroom. I have come to believe that SALT teachers more than any other teachers need a backup, they also need a platform where they can discuss their successes and setbacks and their problems with each other, where they can reenergise and be re-inforced. SALT is fragmented in most countries in Europe for several reasons, an important one being the lack of academic research and training and application. SALT will only achieve the necessary respectability for a wider acceptance once it has been taken seriously by universities. As long as it remains in the hands of business people and enthusiasts it will not enjoy a real future.

In Finland teachers are still searching, investigating and trying out Suggestopedia and they realised from the very start that they have to develop their own brand of SALT. I gave lectures and demonstrations at several universities and colleges as a practising academic, not just a theoretician. The Finns believe that SALT suits their mentality extremely well, but not American SALT or Australian SALT. Therefore they are very eager to develop their own kind, and the universities and colleges invite foreigners to come and teach them. In 1982 the Finnish Society for Accelerative Learning was founded. The need for a backup system and for a discussion platform was immediately realised and acted upon. Peija Ilpola teaches suggestology at the University in Oulu and conducts workshops on request all over Finland. Gabriel Racle (Canada) and Charles Schmid (LIND, USA) have left their mark in Finland, too. 
My research took me to the Federal Republic of Germany (West Germany). I was amazed at how little SALT is known there. The translation of the book "Superlearning" which appeared in 1980 made some Germans jump on a band wagon of which they understood very little. At Bochum University two academics had done some work with SALT, but not enough to make an impact either on the academic world or on the general public. At the Freie Universität Berlin-West suggestopedic experiments have been conducted, showing no significant improvement of suggestopedic teaching over conventional teaching, according to Prof. Dr Ludger Schiffler. The Lozanov Institute which has its head office in Vaduz, Liechtenstein, tried to get established in Cologne, but without success. The appearance of "Lernen ohne Stress" or "Superlearning" on the bookshelves of bookstores changed this picture to a certain extent. Superlearning courses, superlearning games, superlearning cassettes have since appeared on the market in abundance. I examined some of them and was amazed at what their originators consider to be superlearning. As long as SALT remains on that level, it will not become respectable and therefore it will not be accepted by the Germans and most certainly not by German educational authorities. In academic circles there is great scepticism regarding SALT. It is my belief that no outsider will be able to convert West Germany to SALT. The conversion has to come from within. Foreigners who have conducted workshops there have been severely criticised afterwards. Again it is a matter of cultural, educational, political and other differences that inhibit the spread of SALT. I gave lectures at the Universities of Heidelberg and Heilbronn where I came across scepticism on the part of the academics, while the students and the general public quite often responded with an emotional and positive acceptance. But that is not enough. Only scientific data-and there is not enough of it availablemight eventually change the situation for SALT in Germany. I came to the conclusion that as long as SALT is not taught as a methodology in Universities and Teachers' Colleges, as long as its superiority over other more conventional methods cannot be proven by hard scientific data, as long as we rely mostly on emotional responses by teachers and students to the method-and emotions don't last-so long will SALT not have a chance to survive.
My next stop was Vaduz, Liechtenstein, where I visited the newly established Lozanov Institute. The Institute under the direction of Tony Stockwell began its operations in Liechtenstein in January 1984. From 27 August to 15 September a test course was conducted at the high school in Vaduz on the strength of a report from Mr Felix Imhoff, the business director of the Lozanov Institute, and Dr Weiss, the school psychologist of Liechtenstein. After a three hour discussion I held with the latter, two months after the end of the course, I can report the following: The Lozanov Institute entered into negotiations to conduct a suggestopedic experiment in one of the classes of the Liechtenstein high school. A third year class was selected, consisting of 18 boys and girls between the ages of 14 and 16 to be taught English. A number of those students had an interrupted career in their school lives, as some had repeated classes, or they had been in special schools for slow learning students. Very few of them had had any English before. Classes were held daily from $8 \mathrm{a} . \mathrm{m}$. to 1 p.m. except on Saturdays when class ended at 12 noon, with several breaks in the course of a morning. On Monday and Thursday afternoons a programme supplementing the course was offered to the students. The school psychologist as well as the students' regular class teacher were participants at all sessions. Tony Stockwell taught the class. Towards the end of the course the class teacher was included in the teaching to assist the transition from the suggestopedic to the ordinary teaching situation once the course was over. The supplementary programme included English games, like cricket, films and a barbecue. Two important points emerged from this report; there is neither a physical nor a mental relaxation period at the beginning or for that matter at any point in the course. I asked Mr Imhoff about that and he said that the Institute followed Lozanov's present format. He also said that the Institute was kept up to date with the latest developments in the Bulgarian Institute. The second difference from SALT is the passive concert session which is given at the end of every lesson. The course appears to have had all other ingredients of a suggestopedic course, including games, songs and even a play at the end. The school psychologist who admitted that he had never heard of Suggestopedia before he met the directors of the Lozanov Institute was most impressed. He was particularly impressed by the high level of motivation that this method achieved in the students, and particularly in that 
group of generally poorly motivated students. As far as he is concerned the success of the experiment is most obvious in the motivational area. Another very obvious result of the suggestopedic teaching in that class was that it is possible to increase the ability to concentrate even in those students who are markedly deficient in their ability to concentrate. A further positive factor of suggestopedic teaching which the psychologist mentions was that the students learned and applied rules spontaneously and without explicit explanations. The students did not receive any kind of conventional assessment. In order to transfer suggestopedic teaching into the prevailing school system, some form of acceptable assessment will have to be established. Since this first experiment with Suggestopedia was such a success, the psychologist recommended further experiments in language learning and also in reading for first graders. Furthermore, he recommended teacher training courses to enable Liechtenstein teachers to employ this method in their classrooms and thereby experiment with its effectiveness on several levels. The Lozanov Institute has since developed teacher training courses for the Liechtenstein school teachers in addition to its foreign language courses and business and management course. What is missing in this report is any data on actual language acquisition. But comparative tests as well as formal and informal evaluations on student, teacher and parent reaction are to be extensively conducted in the period in future. In his conclusion Tony Stockwell made several points, that he is totally satisfied with the psychological aspects of the course as well as with the established group dynamics and the learning effect. But he had expected more in regard to language ability. He blames the brevity of the course: 98 hours in three weeks. This, however, will be rectified in the second phase. In the Lozanov Institute in Sofia a course stretches over four to six weeks at three and a half hours per day, which seems to be a much better design. Many practising teachers can never teach suggestopedically in an ideal situation, having to make the best of a 50 minute period and therefore making allowances in every aspect of a course. Tony Stockwell's students were so motivated that they expressed a wish to continue their English lessons - an achievement unimagined for that particular group of students. The course was a success even if the expectations of the teacher were not totally fulfilled.
At the end of the course the two directors of the Lozanov Institute held a meeting for 34 teachers and representatives of the Liechtenstein school system where they discussed this school experiment. Mr Stockwell demonstrated to the audience the main elements of the suggestopedic method with practical examples. He stressed the importance of identity change, the dual plane, visualisation whereby he meant drawing a picture of the partner, and visualising text material, body language, student praise and corrections, indirect testing, corrections "via the back door", translations, the two concert sessions, the use of the ball, games and songs. The attending teachers were given ample time to ask questions and discuss all aspects of suggestopedic teaching. The school psychologist summed up his impressions of the experiment by highlighting the very pleasant teaching/learning atmosphere, the high motivation of the children, the ability to concentrate even of those children who have concentration problems in conventionally conducted classes, the type of student who was involved in this experiment, namely those who are school leavers due to poor self-concepts and low achievements, the new framework for the school, the excellent results achieved, the basic attitudes, namely ability, success and joy, the students' predilection for games, the decrease in problems of legasthenic students. To these comments the class teacher added that no problems arose in motivating the students to sing, contrary to experiences he has had in conventional teaching. The same applied to correcting the students' pose. The Liechtenstein government has seconded the headmaster and deputy headmaster for a one year sabbatical to the Institute and a five year plan has been presented by the school authorities for further tests at all school levels in several different subjects.

What follows is a report on the Austrian experiment.

From 1974 to 1978 a four year school experiment with Suggestopedia was conducted in Vienna with the direct involvement of Dr Lozanov and the Austrian Ministry of Education. Two elementary school teachers of two first grade classes who taught reading, writing and arithmetic were trained by Dr Lozanov. He also participated in the preparation of the parents of the pupils involved, and advised and administered the experiment during his extended stays in Vienna or from 
his Institute in Bulgaria. After two and a half years the experiment was assessed and found to be very successful. The following points were found to be most noteworthy:

- higher achievements both quantitatively as well as qualitatively,

- the positive connotation of school, instruction and learning,

- a trust relationship between pupils and teachers,

- steady increase of motivation and creativity,

- a reduction in aggression on the part of the pupils,

- no repeaters in the class, that is, all students passed at the end of the year (in those days approximately $8 \%$ of the pupils repeated the year due to poor performance) and

- increased interest on the part of the parents which indirectly aided the motivation of the children.

On the other hand, a heavy burden was put on the teachers who taught suggestopedically since the teacher not only had to learn the method and how to use it, but also had to produce the teaching and learning aids, individualise instruction, maintain closer contact with the parents of low achievers, and spend much more time and energy in the preparation of lessons. Psychologically the teacher had to trade the certainty and comfort of working with the existing aids for improvisation, pioneering and enormous effort. Ultimately the question remained: will the quickly acquired knowledge be retained over long periods or will it soon be forgotten.

Despite all this the experiment was continued. The Austrian Government concluded a cultural agreement with the Bulgarian Government and the Ludwig Boltzmann Institute for Learning Research was established. But then the problems started, most of them connected with Dr Lozanov himself and his availability or reported non-availability for the projects. No official reasons seem to exist why Suggestopedia à la Lozanov was discontinued as an officially sponsored methodology in Austrian schools. The fact remains that in 1978 the Institute of Psychology under the chairman- ship of Prof. Giselher Guttmann, in co-operation with the Ludwig Boltzmann Institute for Learning Research and the Federal Pedagogical Academy of Vienna, began a school experiment called "Angewandte Lernpsychologie im Unterrichtsgeschehen" (applied learning psychology in the teaching situation). This project was to last initially for four years. I visited the Ludwig Boltzmann Institute in 1981 for the first time and observed several classes in session, and was impressed, particularly since my own teaching career had begun in a small Austrian elementary school in 1954 . What I saw in 1981 was totally unrelated to what I had been taught when I attended teachers' college in Austria. The influence of Dr Lozanov is, of course, very noticeable, even if the developers of this new method do not give him any mention, let alone credit, in their report soon to be published in book form. The following comments are based on this report as well as on my observations during 1981 and 1984.

It is important to point out that acceleration of learning is definitely not the objective of the Austrian method. The report stressed this unequivocally. What the Austrian researchers hope to achieve is the elimination of stress and the fostering of joy in learning, as far as the students are concerned. In regard to research it is the duty of the Austrian pedagogical academies to develop and test new methods and-if found to be valuable - to pass them on to future teachers in the course of their training. Guttmann et al believe that they have developed a basic model for teaching/learning interaction in which they attempted to create conditions for learning, retention and re-call which respond to proven facts in learning research. In the course of four years more than 40 classes from the elementary and secondary level in three federal states took part in this project. Prof Guttmann and Dr Vanecek, both from the Institute of Psychology of the University of Vienna, guided this experiment scientifically. Instead of discussing the theory behind the Guttmann/Vanecek Model, I am going to describe the actual teaching situation. The teachers involved in the project were trained in seminars of a total of 120 hours. Additionally they received constant supervision and further schooling. The training included research in activation, neurophysiology of learning, research in verbal learning, motivation, fear and stress management and social learning. The parents of the pupils in the experimental 
classes needed to be informed too. A minimum of homework was expected from the children considering that the value of homework has never been proven scientifically. This was, of course, unexpected and new for the parents. They were also told about the relaxation training and the purpose of the music their children would now experience in their classes.

The Guttmann/Vanecek Model and its application: The model described here is to be seen as a framework for elementary schools since only in elementary schools do we have a situation where the students have the same teacher throughout the day. At the beginning of every lesson there is a preparation phase consisting of relaxation exercises, whereby the teacher has to decide whether the pupils' activation level needs to be lifted or lowered. In order to increase the activation level the teacher will do one of three things: muscle tension and relaxation exercises according to Jacobson, or activation through games involving movement, or listening to activating music with or without rhythmical movements. In order to lower the activation level the teacher will ask the students to count their breathing while sitting in a relaxed position, or to listen to relaxing music, or to "let music tell stories", whereby relaxing and pleasant imagery can be evoked, or to concentrate on just relaxing (without tensing) the body while in a comfortable position as in autogenic training. Relaxing music has the following characteristics: a slow and adagio-like tempo of a basic pulse of between 60 and 80 beats. The dynamics have to be contained within the range of 20 decibels. As a rule melodic intervals are not to exceed the octave. A regular tempo without rubato or clearly noticeable accelerandi, is another criterion. The selected volume of the chosen music is not to be greater than that of the voice at a softer than normal level (appr. 40 to 50 decibels). All selected pieces were tested by teachers and students in regard to their semantic differential and if any of them deviated from the ideal piece of relaxing music to any noticeable degree, that piece was eliminated. The following pieces were selected:

\section{Relaxing music:}

BEETHOVEN: Romance for Violin and Orchestra, F-major

First movement of the Mathematics Moonlight Sonata

DVORAK:

SMETANA:

BRAHMS:

DVORAK:

GRIEG: tion.
Subject

Writing

Second movement of the Pathétique Sonata

American Stringquartet, Second Movement

GRIEG: Morning from the "Peer Gynt" Suite

MENDELSSOHN: Overture to the Midsummer Night's Dream (End) Nocturne from the Midsummer Night's Dream

SCHUBERT: The Trout Quintet. Second movement

The Moldau (The Spring of the Moldau: Moonshine, The Dance of the Nymphs)

\section{Activating music:} Hungarian Dance No. 5 Slavonic Dance, G-minor American Stringquartet, Fourth Movement

In the hall of the Mountain King

HÄNDEL: Music for the Royal Fireworks

MILHAUD: $\quad$ Braziliera from "Scaramouche"

TSCHAIKOWSKY: Russian Dance (Trepak) from "The Nutcracker"

Immediately after the relaxation a short musical signation is given. Each subject has its own signa-

The following signations are used:

Music (approx. $30 \mathrm{sec}$ )

Schubert: Balletmusic no. 2 from "Rosamunde"

Schubert: Fifth Symphony, Opening theme 
Reading Prokofieff: Peter and the
Wolf

German Language Schubert: Sonatina for Violin and piano in $\mathrm{D}$ major

\section{General Subject:}

Social Studies Leopold Mozart: Fanfare from the Musical Sleigh Ride

General Subject:

Natural Sciences Leopold Mozart: Musical Sleigh Ride

The pupils are told quite frequently of the value of relaxation. Immediately following the signation it appears to be best for the dramatic quality of the lesson for a slide to be shown on an overhead projection or on the blackboard in order to lead them directly into the information phase in total quietness and relaxation. The teachers are free to choose their preferred technique, that is, they can use one or more of the following possibilities: a short lecture by the teacher, an experiment, a discussion, group work, individual work, work with a partner. Any mechanical and routine work is to be avoided. The classroom is, of course, arranged in a way that makes movement and flexibility possible. The detailed formulation of the criterion/criteria of the lesson play an important part in the Guttmann/Vanecek Model. Central to their thinking are the following two criteria:

a) What should the pupils know or be able to do? (knowledge, technique)

b) How well should they know (be able to do) it? (ability, difficulty)

Furthermore, the teachers were taught to think in terms of overall goal and goals within the overall goal. The example given from the subject Social Studies shows the district with 20 streets as the overall goal and four times five streets as four goals within the goal. This aspect demonstrates very clearly the reversal to Lozanov's thinking of "stuffing", of presenting more material than normally.

The information phase is followed by a pause. During that pause anything can be done that is not in any way related to the subject matter. Most often the pupils engage in musical activity, including work with Orff instruments and rhythmic dance.

The next phase consists of the first repetition of the new material in a way that is not boring or repetitious. This is followed by the second pause and then the second repetition, which brings the end of the lesson on day one, a fifty minute lesson. It is now clear that this model is particularly suited for elementary schools where one teacher teaches all subject areas. Instead of musical activities I saw teachers go into arithmetic or reading during the pauses in a first year elementary class. A third repetition takes place on day two and a fourth one after a few days.

One of the most valuable learning aids in this project is the learning card system. It consists of a box with five partitions. Factual material to be learned, for example vocabulary, spelling, rules, formulas, and so on are moved from one section of the box to the next according to how well they have been learned or forgotten. Items that are safely stored in the memory are finally discarded from the box. Research proved clearly that this learning card system was invaluable particularly for the less able children. It enables the pupils to regulate their learning themselves, it avoids overkill of learning material, it gives the pupil a permanent control mechanism of his/her knowledge and it increases motivation noticeably. The teachers discuss with the children which items should be put on the cards. The pupils are also allowed to make individual cards for things that interest them beyond the material presented in class. Instead of boxes the teachers allow the pupils to use envelopes. In the upper classes I saw the students use envelopes marked "to be learned", "to be repeated" and "examination material". The latter contained the question on one side of the card and the answer on the other. The Guttmann/Vanecek manuscript explains in great detail the psychology of the learning card system which I will not discuss here. A card system has been established for general studies, foreign languages and spelling.

The pauses within the lesson are justified by the biochemical processes which are necessary to translate the new information or learning material from the short-term into the long-term memory. As far as the repetitions are concerned the re- 
searches refer to Ebbinghaus' curve of forgetting. The first repetition should not differ much from the original presentation of the new material. For that purpose worksheets and other techniques that make it possible for the teacher to check the work of the pupils are used. The second pause is twice as long as the first one. It is used to review old material. Here the learning card system, question and answer games, pair work, and so on can be employed, to serve long-term repetitions. The second repetition of the new material on day one should include variations from the original input. If about $90 \%$ of the pupils are able to do the second repetition alone without help, then the third repetition is given in the form of homework, otherwise it is done on the following day in class. A few days later a fourth repetition takes place. Long-term repetitions are conducted no sooner than after a fortnight.

The Guttmann/Vanecek Model also includes a peer-tutorial-programme. It need not be discussed here since it was developed in the USA and is already widely used there.

Several controlled experiments have been conducted in Austria using this model and all of them point to a total success.

As I mentioned at the beginning of my discussion of the Austrian experiment, acceleration of learning and thereby going beyond the normal curriculum of the respective class is not an aim of the Guttmann/Vanecek Model. Nevertheless, acceleration of learning took place. On average the pupils covered at least half, in several cases all of the following year's work in one year. More important than the speed-up of learning was to the researchers and teachers the quality of work the pupils achieved, and the side benefits, like improved verbal and written expression in the mother tongue as well as in the foreign language, increased interest in reading, considerably better spelling. Here an interesting observation was made. One group of pupils had been involved in the Lozanov programme. These pupils were $17 \%$ behind the control groups as far as spelling was concerned, because in the suggestopedic classes spelling was almost totally disregarded. Two years of work with the learning card system could not eradicate the spelling deficiency caused by suggestopedic teaching. In Math in the upper years of the elementary school the pupils achieved higher marks compared with the control groups and accelerated their material up to one year. The experimental groups increased their marks by almost $16 \%$

In summary it can be said that the Guttmann/Vanecek Model as tested in 42 classes in three federal states of Austria is a successful model in all aspects of learning that were tested in controlled experiments. It satisfied the teachers, parents and students alike. It proved to be stressfree and enjoyable for the pupils, it increased the quality of their work and accelerated their learning remarkably. Observing several classes at work I could not detect any increase in creativity. In fact I find it quite interesting that in the report on the experiments there is no mention of creativity. It is now in the hands of the Austrian educational authorities and of the politicians to decide whether or not this model will be implemented in the Austrian school system on a general basis. In any case, it will most probably be taught at the teachers' colleges. From then on it will be up to the individual teacher to implement it or not as long as the Ministry of Education has not made an official recommendation.

In summary it can be said that Lozanov's work is now known worldwide. In the West many varying degrees of adaptations, from strong adherence to the 1980 version of Bulgarian Suggestopedia as found in Liechtenstein to the Guttmann/Vanecek Model in Austria that emerged from Lozanov's research but developed in an altogether different direction, many attempts at accelerating learning have been made. The lack of research centres in the West where for instance factual data on the psycho/physiological aspects of learning and teaching could be produced, make accelerative learning not easily acceptable to the majority of people, academics and the general public alike. Additionally, inefficient teacher training and, if available at all, its high costs either cause teachers to give it up too quickly or prevent them from undertaking training at all. Unless we can overcome these obstacles, accelerative learning in any shape or form will remain in the hands of enthusiasts and esoteric teachers and never make a great impact in education.

\section{Bibliography}

BEER, Franz. 1978. Report on the school-experi- 
ment "Suggestopedia in Elementary Schools". Vienna: Ludwig Boltzmann Institut für Lernforschung. (Unpublished manuscript.)

TESTKURS-Lozanov. 1984. Oberschule Vaduz, Fürstentum Liechtenstein. Vaduz: Lozanov Institute.
VANECEK, Erich. 1982. Angewandte Lernpsychologie im Unterrichtsgeschehen: Ein Schulversuch. Vienna: Institute for Psychology, University of Vienna, and the Ludwig Boltzmann-Institut für Lernforschung. (Unpublished manuscript.)

We solemnly affirm that all men are substantially equal.

In every man who believes himself superior to his fellows by nature, there exists a potential racist.

If intelligence is previously fixed in chromosomes, any fight for the establishment of social justice is ultimately useless. 